\title{
The Relationship between English Teacher Misbehaviors in the Classroom and Students' Perception of Teacher Credibility
}

\author{
Lisa, Li-I Hsu \\ Dept. of Applied English, National Taichung University of Science \& Technology \\ No. 129, Section 3, San-Min Rd. Taichung 40401, Taiwan, R. O. C. \\ Tel: 1-886-4-2219-6412Ｅ-mail: hsu31280@gmail.com
}

Received: April 11, 2014 Accepted: April 28, 2014 Published: April 28, 2014

doi:10.5296/ijele.v2i2.5548 URL: http://dx.doi.org/10.5296/ijele.v2i2.5548

\begin{abstract}
This study aimed to examine the effects of English teacher misbehaviors on students' perception of teacher credibility. Three hundred and ninety-eight participants completed a Taiwanese Teacher Misbehavior Scale (TTMS) and a Student Perception of Teacher Credibility Scale. The Pearson's correlation coefficient $(r)$ was computed to examine the relationship of English teachers' four types of misbehavior shown in TTMS: derisiveness, incompetence, irresponsibility, and non-immediacy with students' perception of teacher credibility. The results indicated that English teachers' misbehaviors were correlated negatively and significantly with students' perception of teacher credibility. In addition, the ANOVA test revealed statistically significant results as well. A further MONOVA was computed to examine the effect of interaction among all variables. Results of the analysis of variance revealed two types of teacher misbehavior-incompetency and non-immediacy - best predicted teacher caring, out of the three dimension of teacher credibility. However, there was no significant interaction found on the other two dimensions-competency and trustworthiness. Further discussion and pedagogical implications were addressed.
\end{abstract}

Keywords: teacher misbehaviors, teacher credibility, caring, competency, trustworthiness 


\section{Introduction}

Classrooms are complex societies in themselves, much less English classes where students often feel more anxiety than when attending regular courses conducted in their native language. Teachers are the leaders in these societies. The ways teachers exercise their leadership abilities greatly influence the interactions that take place between teachers and students as well as interactions between the students themselves. These interactions have a significant impact on the academic and social growth of students; furthermore, these influences continue impacting student motivation and affective learning for English. Credibility is an imperative variable that particularly influences the teacher-student relationship. Students encounter difficulties accepting information from sources that lack credibility (Beatty \& Behnke, 1980). The role of source credibility in communication, or in-class lecture delivery has been studied extensively by many researchers (McCroskey \& Teven, 1999; McCroskey \& Young, 1981; Self, 1996; Teven, 2001). Studies have shown that the effectiveness of a persuasive message is partly dependent upon the receiver's perception of credibility of the source or the speaker (Burgoon, 1976; McCroskey \& Teven, 1999; Teven \& Hanson, 2004). Higher source credibility proved to be correlated with greater persuasive effectiveness (McCroskey \& Teven, 1999; Teven, 2007). As a result, teacher credibility is a vital perception students make regarding teacher behavior that ultimately plays a supporting role in student learning. According to Teven and McCroskey's (1997) study, student perception of teacher credibility was found to be significantly associated in a positive manner with the students' evaluation of their teachers, their cognitive learning, and their affective learning. While English teachers are striving for professionalism and effectiveness, these findings should not be overlooked. It is important for all teachers, particularly, in this case, English teachers, to establish and maintain the perception of credibility from the first day of class to the last. Teacher misbehavior is another variable that has been found to have a major impact on students' perception of a teacher in the classroom and on student learning (Banfield, Richmond, \& McCroskey, 2006). Teacher misbehavior leads to negative learning outcomes for students (Teven, 2007). This current study focuses on evaluating four types of teacher misbehavior - derisiveness, incompetence, irresponsibility, and non-immediacy - that Hsu (2013) developed to fit Taiwanese academic culture, examining their impact on three dimensions of perceived teacher credibility - competence, caring, and trustworthiness (Teven \& McCroskey,1997).

\section{Literature Review}

\subsection{Teacher Misbehaviors}

Teacher misbehaviors were originally conceptualized as "those teacher behaviors that interfere with instruction and thus, learning" (p. 310) (Kearney, Plax, Hays, \& Ivey, 1991). Kearney et al. (1991) initiated the line of teacher misbehaviors research by investigating the specific teacher misbehaviors that interfere with teaching and distract students from learning in U. S. college classrooms. In a two-stage investigation, Kearney and colleagues first inductively determined what students perceived as teacher misbehaviors. This study resulted in 1762 descriptions of teacher misbehaviors that were later classified into 28 categories. 
Three factors emerged from the 28 categories and were labeled as incompetence, offensiveness, and indolence. Incompetence consisted of nine categories of misbehaviors, including confusing/unclear lectures, apathy to students, unfair testing, boring lectures, information overload, not knowing the subject matter, foreign or regional accents, inappropriate volume, and bad grammar/spelling. Offensiveness consisted of six categories of misbehaviors including sarcasm/put-downs, verbal abuse, unreasonable/arbitrary rules, sexual harassment, negative personality, and showing favoritism/prejudice. Indolence was associated with a group of misbehaviors, such as absence, tardiness, lack of preparation /disorganization, deviation from syllabus, late return of work, and information underload (Kearney et al., 1991; Kearney, Plax, \& Allen, 2002; McPherson, Kearney, \& Plax, 2006). Students reported that they believed they were learning less in the classroom when a teacher was misbehaving. The result indicated that students have less affective learning, are less likely to engage in classroom discussions, and are less willing to take another course under the same teacher (Dolin, 1995). In Dolin's study, the result showed that teacher's misbehavior frequency was minimal, but it is the impact that is of great concern.

Toale, Thweatt, and McCroskey (2001) replicated the Kearney et al. (1991) study a decade later, analyzing 114 teacher misbehaviors provided by Kearney et al. (1991). The result turned out slightly different. Forty items were further reduced to three underlying factors: irresponsibility, derisiveness, and apathy. Irresponsibility included 16 items: cancels class without notice, is not available during his/her office hours, is unorganized, makes sexual remarks, is behind the schedule according to the syllabus, does not provide current information, does not show up for appointment outside of class, flirts with students, is not prepared for class, does not know the material s/he is teaching, uses poor English, forgets test dates, rushes through the material to get done early, makes sexual innuendoes toward students, does not seem to care about the course, misspells words on the exam. The second factor labeled "derisiveness" included 12 items: embarrasses students, insults students, is sarcastic and rude, is narrow-minded, humiliates students, is angry, picks on students, is moody, is mean, acts prejudiced against some students, is not patient, and yells/screams in class. The third factor of misbehaviors is labeled "apathy." Twelve items were listed: gives tests that are too difficult, is unclear about what is expected, is boring, goes off topic, gives lectures that are confusing, jumps from one subject to another, gives exams that do not relate to the lectures, does not use variety when giving lectures, rambles when giving lectures, gives exams with questions that are unclear, is not enthusiastic when giving lectures, and does not grade fairly.

In a master thesis study carried by Yu (2011), entitled "A Study on Teacher Misbehaviors as Learning Demotivation among EFL Students in Taiwan", 90 items were adopted from Kearney et al's study in 1991. From there, series statistic item-analysis was computed. In addition to Kearney et al's (1991) original 3 factors, a new factor, inappropriate instruction, was named. Forty-five items remained and were used for the main study. Since the description was written from North American students' perspective, the questionnaire was not appropriate for use in this present study. Instead of modifying or adapting an existing instrument from North America, a novel instrument specific to the Taiwanese model was developed. Hsu (2013) developed and validated a scale of perceived teacher misbehaviors 
from the perspective of Taiwanese college students, assessed only on English teachers due to the author specific research interest as well as having a convenient research environment. Hence, this present study utilizing TTMS mainly investigated English teachers only. The scale was developed by carrying out a two-fold approach; the first was to discover how Taiwanese college students identify teacher misbehaviors in the classroom. The second aspect was to develop initial constructs to measure teacher misbehaviors that appropriately fit Taiwanese culture. After being thoroughly compared with previous existing questionnaires that were developed by Kearney and Toale (Kearney et al. 1991; Toale et al., 2001), four factors were labeled: derisiveness (10 items), incompetence ( 9 items), irresponsibility (5 items), and non-immediacy (4 items).

Teachers in Taiwan are highly respected due to Chinese cultural traditions and values that lie within Confucianism. This mentality also fosters teachers' classroom behaviors that preserve the status of their power and prestige. This, in turn, is demonstrated in the educational setting with classrooms being authority-centered and by the existence of a large power distance between the teacher and students (Andersen, 2000). In light of cultural impact, teachers are considered to be the authority, a learned scholar with absolute knowledge. Asking the teacher a question may be viewed as challenging authority and might potentially cause teachers to lose face especially when teachers don't know the answer (Hsu, 2012). A teacher exhibiting a distant relationship with students is a common scene in the Taiwanese classroom. This logically explains why Taiwanese students perceive their teachers as non-immediate. The last factor, non-immediacy, continuously appeared while conducting factor analysis in different stages in Hsu's (2013) study, whereas this particular behavior didn't appear in North American studies. This outcome demonstrates how crucial it is to develop an instrument that truthfully reflects the impact of Taiwanese culture on student's perception of teacher misbehaviors.

Teacher misbehaviors are negatively associated with student motivation (Christophel \& Gorham, 1995; Hsu, 2014; Myers, 2002), satisfaction with and affect for the course and the instructor (Banfield et al., 2006), cognitive learning (Myers, 2002), and are also linked to teacher non-immediacy (Thweatt \& McCrosky, 1996), low teacher credibility (Banfield et al., 2006), and negative evaluations (Schrodt, 2003). Thus far, relevant research has only been conducted in western institutions, and teacher misbehaviors have only been described from a North American perspective. A thorough investigation on Taiwanese English teacher misbehavior and its impact on students' perception of English teacher credibility are essential and need a further examination.

\subsection{Teacher Credibility and Its Impact on Learning}

According to Thweatt and McCrosky (1998), Aristotle referred to credibility as ethos and suggested that it consisted of three dimensions: intelligence, character, and goodwill. He believed that these three dimensions of credibility were perceptual sources of influence on a receiver. In a later study on the analysis of ethos and credibility, McCroskey and Young (1981) concluded that "contemporary research generally has supported the proposition that source credibility is a very important element in the communication process where the goal of the communication effort is persuasion or the generation of understanding" (p.24). In the 
educational context, if students perceive their teacher as credible, then the teacher has more influence on them in the creation of understanding (Pogue \& Ahyun, 2006). The impact surmised from "the generation of understanding" is most relevant to the effects of credibility in the classroom. One major goal for teachers is to spark understanding in the minds of their students. An effective teacher hopes to see that students develop positive affect toward him/her and the subject matter that is being studied. Andersen's (1973) study showed that teachers who are perceived to be more credible will produce a more positive affect toward themselves and/or the content of the class. Furthermore, it will increase the students' likelihood to take another class in the same content area and/or with that teacher. As a matter of fact, its impact continues to show that students' cognitive learning is related to their perception of their teacher's credibility. The higher the credibility a teacher demonstrated, the more learning a student achieved. Another study indicates that if students do not perceive a teacher to be credible, they are likely to listen less and learn less from that teacher (McCroskey, Holdridge \& Toomb, 1974).Teacher credibility can have a positive impact on students' learning is clear at this point. However, there is little research in the Taiwan educational realm that neither offers advice nor have help teachers increase their credibility. According to related literature review (Banfield et al., 2006; McPherson et al., 2006; Teven \& Hanson, 2004), there could be a correlation between teacher misbehaviors and teacher credibility.

The nature of the three components of credibility was elucidated clearly by Aristotle and then afterwards by Hovland, Janis, and Kelley (1953). They suggested that credibility's theoretical dimensions were competence, character, and goodwill or intention. These three dimensions changed only slightly over the years and have been named as competence, trustworthiness, and caring (Toale \& Thweatt, 2000). Competence consists of one's possessing knowledge or expertise of a particular subject. In other words, if a teacher is to be perceived as competent, he/she should know his/her content well. Competent teachers explain complex material well and clearly, have good classroom management skills, have the ability to answer questions, and communicate effectively (Teven \& Hanson, 2004). Trustworthiness is the degree to which students put reliance on a teacher. A teacher who is high in trustworthiness offers rational explanations for grading, treats students fairly, gives immediate feedback, and never embarrasses students or verbally abuses students because of his/her behavior. Put another way, if students perceive that their teacher is not being trustworthy, that teacher would likely be less credible. Caring is seen as a means of opening communication channels more widely (McCroskey \& Teven, 1999). Caring teachers communicate in such a way that students perceive they are being taken care of, and are more likely to perceive their teacher to be more credible (Teven \& Hanson, 2004).

Teacher caring was found in many studies to be positively correlated to students' perception of teacher immediacy, responsiveness, and assertiveness whereas negatively correlated to teacher verbal aggressiveness (Myers, 2001; Teven, 2001; Teven \& Hanson, 2004; Thweatt \& McCroskey, 1998). In Myers' study of perceived instructor credibility and verbal aggressiveness, it was concluded that perceived instructor competence, trustworthiness, and caring are all negatively related with perceived instructor verbal aggressiveness. In other words, the more teachers use aggressive verbal messages, the less credible and caring 
students perceive their teacher to be. While a great number of studies have shown that teacher misbehaviors are one of the main causes in decreasing teacher's teaching effectiveness (Murray, 1991) and impact student's satisfactory learning outcome (Banfield et al., 2006), an in-depth investigation of Taiwanese English teacher misbehaviors is crucial and worthy of further research. To date, examinations of the effects of teacher misbehaviors on students' perception of teacher credibility is limited to North American college classrooms.

The rationale of this study is to show how student perceived teacher credibility is associated with teacher's misbehavior in the classroom, particularly in an English classroom. Based upon this concept, this study has two research questions:

RQ 1: Are English teacher derisiveness, incompetence, irresponsibility, and non-immediacy misbehavior types associated with students' perception of teacher credibility?

RQ 2: If the answer to RQ1 is "yes" for any or all of the credibility dimensions, then how do different teacher misbehaviors impact students' perception of teacher credibility?

\section{Method}

\subsection{Participants}

For the present study, participants consisted of 398 English major students (82 male, 21\%, and 316 female, 79\%) drawn from the English Department of several central Taiwan Universities that generally have more females than males in its student population. Students enrolled in English courses participated voluntarily in this study. Seventeen different courses related to English language learning were reported by the respondents. The participants consisted of 143 freshmen (35.9\%), 62 sophomores (15.6\%), 130 juniors (32.7\%), and 63 seniors $(15.8 \%)$, with a mean age of $21.72, \mathrm{SD}=5.84$.

\subsection{Procedure}

An on-line questionnaire was developed to collect the data in order to avoid any discomfort for teachers who were willing to help with data collection. The author sent an invitation and survey link to twelve colleagues and several teachers at other colleges, asking for their assistance. The author suggested that teachers asking students to take this survey should hold their class in a computer lab for the purpose of increasing the response rate. Data was collected in the last week of the semester to ensure that students had been very well acquainted with the class and the teacher communication behaviors. Participants were recruited from English courses, and participation was confidential and anonymous. No extra credit was granted for participation. Participants were asked to complete two scales, measuring their observation of the teacher misbehaviors and their perception of teacher's credibility. The questionnaire took approximately 15-20 minutes to complete. In order to avoid data collection problems or potential bias, the students were asked not to rate the teacher in the class in which they received the questionnaire; rather, their descriptions of teacher's misbehavior and perception of teacher credibility were to focus on several or many of their English teachers during their entire college life. 


\subsection{Instruments}

Students completed two instruments. The first instrument measured students' observation of their teacher's misbehaviors in the classroom. The second instrument assessed students' perception of teacher credibility. The instruments were translated into Chinese-to-English and English-to-Chinese, the Werner and Campbell (1970) back-translation method was employed in this study. Three bilingual scholars involved in this stage of back-translation and ensured linguistic and conceptual equivalence. The instruments are presented in Appendixes 1 and 2.

\subsubsection{Measure of Teacher Misbehaviors}

Teachers' misbehavior was measured by adapting and utilizing Hsu's newly developed teacher misbehaviors scale-Taiwanese Teacher Misbehaviors Scale (TTMS) (Hsu, 2013), consisting of 28 items of teacher misbehaviors. Students were asked to report the frequency of their English teachers exhibition of these behaviors on a 5-point Likert-type scale, from 1 (never) to 5 (very often). The alpha reliability for this present study was .971 with $\mathrm{M}=51.37$ and $\mathrm{SD}=20.08$.

\subsubsection{Measure of Teacher Credibility}

The student's perception of teacher's credibility was measured by using an 18-item scale developed by Teven and McCroskey (1997). It is a 7-point bipolar scale. Each dimension was measured with responses to six descriptions. Cronbach's alphaafor this present study is .963 . For each component of competence, caring, and trustworthiness was $.890, .918$, and .943 respectively. A detailed report of the instruments is presented in Table 1.

Table 1. Characteristics of Instruments $(\mathrm{N}=398)$

\begin{tabular}{lcccc}
\hline Instruments & $\begin{array}{c}\text { Number } \\
\text { of Items }\end{array}$ & $\begin{array}{c}\text { Reliability } \\
\alpha\end{array}$ & Mean & SD \\
\hline TTMS & 28 & .971 & 51.37 & 20.08 \\
Credibility & 18 & .963 & 91.50 & 22.99 \\
$\quad$ competence & 6 & .890 & 30.72 & 8.35 \\
$\quad$ caring & 6 & .918 & 28.29 & 8.01 \\
$\quad$ trustworthiness & 6 & .943 & 32.48 & 8.36 \\
\hline
\end{tabular}

\subsection{Data Analysis}

This study was designed to examine the effects of teacher misbehaviors on students' perception of teacher credibility. The data was subjected initially to Pearson's correlations and one-way analysis of variance. To further examine the data, the data was subjected to two-way multivariate analyses of variance. Alpha for tests was set at $.001, .01$, and .05 on different analysis. 


\section{Results}

To answer research question one, the Pearson's correlation coefficient $(r)$ was computed first to examine the relationship of teacher's derisiveness, incompetence, irresponsibility, and non-immediacy with students' perception of teacher credibility. The results indicated the relationship between these four types of teacher misbehavior and students' perception of teacher credibility was significantly and negatively associated with coefficient $r$ value respectively at $-.621,-.690,-.552,-.620, p<.01$.Approximately $30 \%$ to $48 \%$ of variance was accounted for by each type of misbehavior. An independent sample one-way analysis of variance (ANOVA) was computed to examine the effect of the independent variable (derisiveness, incompetence, irresponsibility, and non-immediacy) on the dependant variable (students' perception of teacher credibility). The ANOVA revealed statistically significant results from derisiveness $F(33,364)=8.997, p=.000, p<.001$, incompetence $F(33,364)=$ $11.687, p=.000, p<.001$, irresponsibility $F(16,381)=13.647, p=.000, p<.001$, and non-immediacy $F(15,382)=18.143, p=.000, p<.001$. Table 2 displayed the summary.

Table 2. Summary of ANOVA for Four Types of Teacher Misbehaviors Impact on Students' Perception of Teacher Credibility

\begin{tabular}{llccccc}
\hline \multicolumn{1}{c}{ Variables } & Source & \multicolumn{1}{c}{ SS } & df & MS & F & $P$ \\
\hline Derisiveness & Between & 94333.08 & 33 & 2858.58 & 8.997 & $.000 * * *$ \\
& Within & 115646.41 & 364 & 317.71 & & \\
& Total & 209979.49 & 397 & & & \\
Incompetence & Between & 108023.27 & 33 & 3273.43 & 11.687 & $.000 * * *$ \\
& Within & 101956.22 & 364 & 280.10 & & \\
& Total & 209979.49 & 397 & & & \\
Irresponsibility & Between & 76497.21 & 16 & 4781.08 & 13.647 & $.000 * * *$ \\
& Within & 133482.28 & 381 & 350.35 & & \\
& Total & 209979.49 & 397 & & & $.000 * * *$ \\
Non-immediacy & Between & 87358.69 & 15 & 5823.91 & 18.143 & \\
& Within & 122620.80 & 382 & 321.00 & & \\
& Total & 209979.49 & 397 & & & \\
\hline
\end{tabular}

$* * * p<.001$

To further address research question two, the data was subjected to a two-way multivariate analyses of variance (MONOVA). It was anticipated that the independent variables (four types of teacher misbehaviors) would impact the dependant variable (students' perception of teacher credibility) to a different degree. Box's Test of Equality of Covariance Matrices was not significant, $(\mathrm{M}=25.18, \mathrm{~F}=1.684, p=.082>.05)$ and the data did not violate the 
assumption of homogeneity of variance. The result of the MONOVA revealed a significant interaction effect. A significant multivariate main effect was observed for level of "caring" on perception of teacher incompetence $(p=.003, p<.05)$ and teacher non-immediacy $(p=.007, p$ $<.05$ ). Wilk's Lambda was conducted for the verification of MONOVA on the dimension of teacher caring; Wilk's Lambda $=.156, \mathrm{~F}(4,104)=1.404, p=.017, p<.05, f^{2}=.371$. The details of the MONOVA are presented in Table 3.

Table 3. Summary of MONOVA Interaction between Caring and Teacher Misbehaviors

\begin{tabular}{|c|c|c|c|c|c|c|c|}
\hline $\begin{array}{l}\text { Dependent } \\
\text { variable:Caring }\end{array}$ & $\begin{array}{l}\text { Type III } \\
\text { SS }\end{array}$ & $\mathrm{df}$ & MS & $\mathrm{F}$ & Sig. & $5^{2}$ & Observed power ${ }^{\mathrm{a}}$ \\
\hline Derisiveness & $648.00^{\mathrm{b}}$ & 26 & 24.92 & .62 & .909 & .898 & 1.000 \\
\hline Incompetence & $1351.62^{c}$ & 26 & 51.99 & 2.31 & .003 & .941 & 1.000 \\
\hline Irresponsibility & $173.15^{\mathrm{d}}$ & 26 & 6.66 & .76 & .784 & .860 & .994 \\
\hline Non-immediacy & $272.98^{\mathrm{e}}$ & 26 & 10.50 & 2.13 & .007 & .932 & 1.000 \\
\hline
\end{tabular}

${ }^{\mathrm{a}}$ Computed using alpha $=.05$

${ }^{\mathrm{b}} \mathrm{R}^{2}=.898$ (Adjusted $\mathrm{R}^{2}=.366$ )

${ }^{\mathrm{c}} \mathrm{R}^{2}=.941$ (Adjusted $\mathrm{R}^{2}=.633$ )

${ }^{\mathrm{d}} \mathrm{R}^{2}=.860$ (Adjusted $\mathrm{R}^{2}=.129$ )

${ }^{\mathrm{e}} \mathrm{R}^{2}=.932$ (Adjusted $\mathrm{R}^{2}=.580$ )

\section{Discussion}

The purpose of this study was to examine the relationship between English teacher misbehaviors in the classroom and students' perception of teacher credibility. Two research questions were posed. The first research question inquired whether teacher derisiveness, incompetence, irresponsibility, and non-immediacy misbehavior were correlated with students' perception of teacher credibility. Results showed that student perception of teacher credibility was negatively associated with teacher's derisiveness, incompetence, irresponsibility, and non-immediacy to a significant level. This result suggest that the more the teacher demonstrated or presented these four types of misbehavior, the more likely the 
student had a negative perception of teacher credibility. The variance of influence accounted for by these four types of misbehaviors was derisiveness $39 \%$, incompetence $48 \%$, irresponsibility 30\%, and non-immediacy $38 \%$. Additionally, an independent sample one-way analysis of variance also indicated statistically significant effect from all four types of misbehavior and their impact on student perception of teacher credibility $\mathrm{F}(71,326)=.634$, $p=.000, p<.001$. The answer to the first question is clear, yes, teacher derisiveness, incompetence, irresponsibility, and non-immediacy misbehavior impact student perception of teacher credibility. This result is not surprising since many studies have demonstrated a correlation between teacher misbehaviors and student perception of teacher credibility (Banfield et al., 2006; Teven \& Hanson, 2004; Thweatt \& McCroskey, 1998). The present study confirms that, in the Taiwan educational realm, student perception of teacher credibility is correlated with teacher misbehavior.

As a follow up to the "yes" result of the first research question, the second research question asked whether the four primary predictor variables would interact in forming student perception of teacher credibility. In other words, the author intended to determine how these four types of misbehaviors interacted with three dimensions-competence, caring, and trustworthiness - on student perception of teacher credibility. The MONOVA result revealed that only the "caring" dimension had a significant interaction with two predictor variables-incompetence, and non-immediacy. This result can be interpreted that students perceived the teacher to be less credible in the caring dimension when the two types of teacher misbehavior were presented. However, the caring component of teacher credibility was impacted differently by each teacher misbehavior type. Students' perception of teacher caring was affected most by incompetence, followed by non-immediacy, derisiveness, and then irresponsibility. Variance accounted for by each type of misbehavior was $63 \%, 58 \%$, $37 \%$, and $13 \%$ respectively. In light of these results, it may be worth remembering the old saying, "Students don't care how much you know until they know how much you care."

Surprisingly, teacher competence and trustworthiness had no interaction with any predictor variables. Does this mean that any teacher misbehavior would fail to influence student perception of teacher credibility? Statistically, there is no interaction between these variables. One thing is certain, student perception of caring interacts to some degree with teacher incompetence and non-immediacy. What would a competent and immediate teacher do? Maybe a review should be made of the kinds of behaviors were seen as incompetent and non-immediate with respect to the current study. Specifically for English teachers, incompetence includes: Translating poorly from the textbook, being disorganized, not explaining clearly, not providing new knowledge, not teaching according to students' level, repeatedly using the same teaching material, not preparing for class, reading word-for-word, being unable to control the class, and not creating interest in study. Non-immediacy includes: Never changing teaching methods, boring classes, not remembering or wrongly calling students' names, not communicating with students during break or after class, and not showing any interest in knowing more about how the students are doing. Hsu's (2013) study found non-immediacy type of misbehavior was strongly exhibited in the Taiwanese college classroom. Teachers had a very significant impact on student learning motivation. However, this particular type of misbehavior has never been shown in any existing research that was 
reviewed from North America. The author assumed there is a cultural influence because of Taiwanese emphasis on Confucianism which plays a role in all these findings. Under the influence of Confucianism, teachers tend to embrace a larger power distance which results in reluctance to freely communicate with students during the break or outside of the classroom (Hsu, 2012).

Teacher immediacy is defined as approachable behavior, which results in the perception of interpersonal closeness, warmth, and friendliness (Rodriguex, Plax \& Kearney, 1996), thus reducing students' communication anxiety and increasing their motivation for learning English (Hsu, 2010). Conversely, non-immediacy behaviors convey lack of enthusiasm and expressiveness, such as "low eye contact, a distal position, backward leaning body, and the absence of smiling and touch, communicated greater detachment" (Sanders \& Wiseman, 1990, p.342). Teacher non-immediacy was related to the amount of teacher misbehaviors. In other words, teacher non-immediacy created less friendly, more distant teacher-student interactions that resulted in higher anxiety, less willingness to engage in classroom participation, and possibly lead to lower motivation and less interest in learning.

Why does the caring dimension have a significant interaction with teacher incompetence and non-immediacy? If we review how caring was being interpreted, the outcome is sensible. Caring teachers communicate in a way such that students feel they are being cared about (Teven \& Hanson, 2004). This is not an abstract assumption but a concrete idea that can be grasped. What would a caring teacher do? Obviously, they would NOT display incompetence nor non-immediacy, but competence and immediacy. For instance, teachers always demonstrate their passion for teaching that includes coming to class with a well-prepared lesson plan, trying to interact with students while teaching, and expressing their concern for the classroom atmosphere. Above all, the outcome of this study allows the author to state that teacher's incompetence and teacher non-immediacy has a stronger impact than derisiveness and irresponsibility on the perceived caring dimension.

\subsection{Pedagogical Implications, Limitations and Suggestions}

The implication of this study for English teachers should be clear. The teacher should attempt to be more competent in his/her expertise, seeking varied teaching approaches, meanwhile increasing students' learning interest by meeting their special needs and not using a one-size-fits-all type of teaching approach. Never underestimate students' sensibilities, without a well prepared lesson, the teacher should not step on the podium. The teacher should also put more emphasis on immediacy, take time to remember students' names, show concern for their study, as well as be aware of the classroom atmosphere and morale of the class and what caused it. He/she should make small talk before and after the class, and try to interact or communicate the students outside of class time. According to the results of this study, the teacher will be perceived as more credible and caring, particularly when the teacher demonstrates these behaviors. In turn, students may be subsequently able to achieve greater learning outcomes when teachers are better able to improve their own behavior in the classroom (Gorham \& Zakahi, 1990).

The first, obvious limitation of this study is the sample obtained consisted of students from 
one university. Second, a limitation of this present study is its way of collecting data by asking students' perception of teacher credibility and observation of teacher misbehaviors rather than actual counts of teacher misbehaviors. Third, this type of research can never establish causality between teacher misbehaviors and teacher credibility; only correlation.

The forth limitation that could occur in this study is the participant's potential loss of recall or confusion while completing the scales, causing a further bias of the result. Another and final limitation is drawing of the sample from only the English Department and only assessing English teachers. Hence, the outcome may only apply to a limited part of the faculty. Also the generalizability of the results in this current investigation must be determined in subsequent research. Future research should be replicated in other groups of teachers who teach different courses. Future research should aim at studying and observing teacher's behaviors in a naturalistic setting. Another suggestion for future study should determine the actual impact that teacher misbehaviors have on students' affective and cognitive learning. Bearing that in mind, teachers may be able to apply the results to their actual teaching. In spite of these limitations, this research repeatedly emphasizes the importance of teacher misbehaviors on students' perception of teacher credibility.

Acknowledging that misbehaviors happen in the classroom and identifying them is seldom done due to the "face" issue. Given the movement toward more accountability in higher education and a focus on improving instructional quality, college faculty would do better by understanding misbehavior actually occurring in the classroom intentionally or non-intentionally. There is no shame or guilt if some misbehavior finds their way into the classroom. The result of this study will hopefully serve as a wake-up call, helping educators - specifically English teachers in this case-to communicate caring. This could greatly influence students' perception of teacher credibility, enhance student learning, and also foster positive evaluation of teachers by students.

\section{References}

Andersen, P. A. (1973, November). An experimental study to assess the effects of source credibility on comprehension. Paper presented at the annual convention of the Speech Communication Association, New York.

Andersen, P. (2000). Cues of culture: The basis of intercultural differences in nonverbal communication. In L. A. Samovar, \& R. E. Porter (Eds.), Intercultural communication: A reader, $\left(9^{\text {th }}\right.$ ed., pp. 258-270). Belmont, CA: Wadsworth.

Banfield, S. R., Richmond, V. P., \& McCroskey, J. C. (2006). The effect of teacher misbehaviors on teacher credibility and affect for the teacher. Communication Education, 55, 63-72. http://dx.doi.org/10.1080/03634520500343400

Beatty, M. J., \& Behnke, R. R. (1980). Teacher credibility as a function of verbal content and paralinguistic cues. Communication Quarterly, 28, 55-59. http://dx.doi.org/10.1080/01463378009369358

Burgoon, J. K. (1976). The ideal source: A re-examination of credibility measurement. Central States Speech Journal, 27, 200-206. http://dx.doi.org/10.1080/10510977609367893

Christophel, D. M., \& Gorham, J. (1995). A test-retest analysis of student motivation, teacher 
immediacy, and perceived sources of motivation and demotivation in college classes. Communication Education, 44, 292-306. http://dx.doi.org/10.1080/03634529509379020

Dolin, D. J. (1995). Ain't Misbehavin': A study of teacher misbehaviors, related to communication behaviors, and student resistance. Unpublished doctoral dissertation, West Virginia University, Morgantown.

Gorham, J., \& Zakahi, W. G. (1990). A comparison of teacher and student perceptions immediacy and learning: Monitoring process and product. Communication Education, 39, 354-268. http://dx.doi.org/10.1080/03634529009378815

Hovland, C. L., Janis, I. L., \& Kelley, H. H. (1953). Communication and Persuasion. New Haven, Connecticut: Yale University Press, 1953.

Hsu, L. (2010). The impact of perceived teachers' nonverbal immediacy on students' motivation for learning English. Asian EFL Journal, Special Issue, 12(4), 189-205.

Hsu, L. (2012). Causes of student unwillingness to talk in English classes. Journal of the National Taichung Institute of Technology, 16, 101-114.

Hsu, L. (2013). Development and Validation of a Questionnaire to Assess Taiwanese Teacher Misbehavior in the Classroom. Taipei, Taiwan: Bookman Books, Ltd.

$\mathrm{Hsu}$, L. (in press). The relationship between Taiwanese English teacher misbehaviors and college student motivation in English classes. Journal of Applied English, Ming Chuan University.

Kearney, P., Plax, T. G., \& Allen, T. H. (2002). Understanding student reactions to teachers who misbehave. In J. L. Chesebro \& J. C. McCroskey (Eds.), Communication for teachers (pp. 127-140). Boston: Allyn \& Bacon.

Kearney, P., Plax, T. G., Hays, E. R., \& Ivey, M. J. (1991). College teacher misbehaviors: What students don't like about what teachers say or do. Communication Quarterly, 39, 309-324. http://dx.doi.org/10.1080/01463379109369808

McCroskey, J. C., Holdridge, W., \& Toomb, J. K. (1974). An instrument for measuring the source credibility of basic speech communication instructors. Speech Teacher, 33, 26-33. http://dx.doi.org/10.1080/03634527409378053

McCroskey, J. C. \& Teven, J. J. (1999). Goodwill: A reexamination of the construct and its measurement. Communication $\quad$ Monographs, 66,90-103. http://dx.doi.org/10.1080/03637759909376464

McCroskey, J. C. \& Young, T. J. (1981). Ethos and credibility: The construct and its measurement after three decades. Central States Speech Journal, 32, 24-24. http://dx.doi.org/10.1080/10510978109368075

McPherson, M. B., Kearney, P., \& Plax, T. G. (2006). College teacher misbehaviors. In T. P. Mottet, V. P. Richmond, \& J. C. McCroskey (Eds.), Handbook of instructional communication: Rhetorical and relational perspectives (pp. 213-234). Boston: Allyn \& Bacon.

Murray, H. G. (1991). Effective teaching behaviors in the college classroom. In J. C. Smart (Ed.) Higher education: Handbook of theory and research (pp. 135-172). Bronx, NY: Agathon Press. 
Myers, S. A. (2001). Perceived instructor credibility and verbal aggressiveness in the college classroom. Communication Research Reports, 18, 354-364. http://dx.doi.org/10.1080/08824090109384816

Myers, S. A. (2002). Perceived aggressive instructor communication and student state motivation, learning, and satisfaction. Communication Reports, 15, 113-121.http://dx.doi.org/10.1080/08934210209367758

Pogue, L.L., \& Ahyun K. (2006). The effect of teacher nonverbal immediacy and credibility on student motivation and affective learning. Communication Education, 55, 331-344. http://dx.doi.org/10.1080/03634520600748623

Rodriguez, J. I., Plax, T. G., \& Kearney P. (1996). Clarifying the relationship between teacher nonverbal immediacy and student cognitive learning: Affective learning as the central causal mediator. Communication Education, 293-305. http://dx.doi.org/10.1080/03634529609379059

Sanders, J. A., \& Wiseman, R. L. (1990). The effects of verbal and nonverbal teacher immediacy on perceived cognitive, affective, and behavioral learning in the multicultural classroom. Communication Education, 39, 341-353.

Schrodt, P. (2003). Students' appraisals of instructors as a function of students' perceptions of instructors' aggressive communication. Communication Education, 52, 106-121. http://dx.doi.org/10.1080/03634520302468

Self, C. C. (1996). Credibility. In M. B. Salwen \& Don W. Stacks, An integrated approach to communication theory and research (pp. 421-441). Mahwah, NJ: Lawrence Erlbaum.

Teven, J. J. (2001). The relationships among teacher characteristics and perceived caring. Communication Education, 50, 159-169.http://dx.doi.org/10.1080/03634520109379241

Teven, J. J. (2007). Teacher caring and classroom behavior: Relationship with student affect and perceptions of teacher competence and trustworthiness. Communication Quarterly, 55, 433-450. http://dx.doi.org/10.1080/01463370701658077

Teven, J. J., \& Hanson, T. L. (2004). The impact of teacher immediacy and perceived caring on teacher competence and trustworthiness. Communication Quarterly, 52, 39-53. http://dx.doi.org/10.1080/01463370409370177

Teven, J. J., \& McCroskey, J. C. (1997). The relationship of perceived teaching caring with student learning and teacher evaluation. Communication Education, 46, 1-9. http://dx.doi.org/10.1080/03634529709379069

Thweatt, K. S., \& McCroskey, J. C. (1996). Teacher nonimmediacy and misbehavior: Unintentional negative communication. Communication Research Reports, 13, 198-204. http://dx.doi.org/10.1080/08824099609362087

Thweatt, K. S., \& McCroskey, J. C. (1998). The impact of teacher immediacy and misbehaviors on teacher credibility. Communication Education, 47, 348-358. http://dx.doi.org/10.1080/03634529809379141

Toale, M. C., Thweatt, K. S. (2000, March). The impact of teacher clarity and teacher misbehaviors on student perceived teacher credibility. Paper presented at the Southern States Communication Association conference, New Orleans, LA. 
Toale, M. C., Thweatt, K. S., \& McCroskey, J. C. (2001, November). Factor analysis 114 teacher misbehavior items. Paper submitted for presentation at the National Communication Association Conference, Atlanta, GA.

Werner, O., \& Campbell, D. (1970). Translating, working through interpreters, and the problems of decentering. In R. Naroll, \& R. Cohen (Eds.), A handbook of method in cultural anthropology. New York: American Museum of Natural History.

Yu, C. Y. (2011). A study on teacher misbehaviors as learning demotivation among EFL students in Taiwan. Unpublished master's thesis, University of Providence, Taichung, Taiwan.

\section{Appendixes}

\section{Appendix 1. Taiwanese Teacher Misbehaviors Scale}

Instructions: Below are a series of descriptions of behaviors some English teachers have been observed saying and/or doing in English classes. Please do not rate the teacher in the class in which you received this questionnaire; rather, your descriptions of teacher's misbehavior was to focus on several or many of your English teachers during your entire college life. For each item, indicate how often your teacher engages in those misbehaviors when teaching. Please use the following scale:

$$
1=\text { never; } 2=\text { rarely; } 3=\text { occasionally; } 4=\text { often; } 5=\text { very often }
$$

1. When the teacher talks about a student he/she

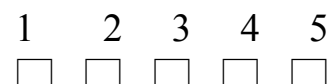
doesn't like, he/she is critical, picky or cold.

2. The teacher doesn't believe in, doesn't encourage, or doesn't acknowledge a student's achievement.

3. The teacher indirectly criticizes a student (singles out one person to actually criticize another) or uses a roundabout way to force a student to drop out of school.

4. When students in the teacher's class have problems with study or don't test well, the teacher uses words that either criticize or laugh at the students.

5. When the teacher evaluates the student's work, he/she uses sarcastic words or personal opinions (For example, the teacher shakes his/her head or says the student doesn't have a bright future.)

6. The teacher always thinks he/she is correct and students are wrong (looks down on the students).

7. The teacher is subjective, doesn't allow the students any room to discuss anything with him/her; he/she can't accept any opinion other than his/hers and his/her facial expressions show impatience or scoffing.

8. When the teacher answers the student's question he/she makes the student feel stupid. (For example, the teacher says the student's question is very simple 
or doesn't want to answer the student's question.)

9. When the teacher answers questions, he/she lacks passion, acts impatiently, or answers just enough to get by.

10. The teacher compares the students' grades.

11. The teacher translates word-for word from the textbook and the translation doesn't sound smooth.

12. The teacher doesn't organize or plan for his/her teaching.

13. The teacher's explanations are not clear, or his/her explanations are self-contradictory.

14. The teacher isn't open to receiving new knowledge.

15. The teacher doesn't teach according to the student's level. (For example, teaches lessons that are too difficult or too easy.)

16. The teacher uses the same teaching material year after year and doesn't update his/her teaching material or content of the class.

17. The teacher has not prepared for class before he/she teaches the class.

18. The teacher reads word-for-word from the textbook.

19. The teacher can't control the class or create interest to study in the classroom (For example, the students sleep or do other things in class).

20. The teacher dozes off during students reports or when monitoring exams.

21. The entire semester the teacher shows movies, requiring students to give summaries, but doesn't give any explanation nor provide Chinese subtitles.

22. At the last minute without notifying the students, the teacher asks for leave, makes up classes or does not show up for class.

23. During the class, the teacher does his/her own work (For example, reads novels, uses the internet, looks at stocks, or uses an iPad.)

24. The teacher is not consistent when giving grades and doesn't explain beforehand how points will be deducted. (For example, absenteeism or sleeping in class.)

25. The teacher never changes teaching methods. The class is boring, always the same, and not attractive.

26. The teacher doesn't remember or wrongly calls the names of the students. He/she doesn't care who the students are.

27. Neither during the break nor after class does the teacher communicate with students in order to get to know them. 
28. The teacher is uninterested in how the students are studying or in the study atmosphere of the class. (For example, the teacher is unconcerned about the high or low attendance of the class.)

\section{Appendix 2. Student Perception of Teacher Credibility Scale}

Directions: Please respond to the following scales in terms of the English class you are taking which meets immediately before the class you are now in. Circle one number on each set of bipolar scales to indicate your judgment of the concept/idea about your English teachers. Note that in some cases the most positive number is a " 1 " while in other cases it is a "7." Please work quickly; there is no right or wrong answer.

Competence

$\begin{array}{lll}\text { Intelligent } & 1234567 & \text { Unintelligent } \\ \text { Untrained } & 1234567 & \text { Trained } \\ \text { Expert } & 1234567 & \text { Inexpert } \\ \text { Competent } & 1234567 & \text { Incompetent } \\ \text { Stupid } & 1234567 & \text { Bright } \\ \text { Informed } & 1234567 & \text { Uninformed }\end{array}$

Caring

Cares about me

1234567

1234567

Has my interest at heart

Insensitive

1234567

Not understanding

Unresponsive

1234567

1234567

Understands How I feel

1234567

Trustworthiness

Sinful

1234567

Dishonest

Moral

1234567

1234567

1234567

1234567

Untrustworthy

Straight-forward
Doesn't care about me

Doesn't have at heart my interest

Sensitive

Understanding

Responsive

Doesn't understand how I feel

\section{Copyright Disclaimer}

Copyright reserved by the author(s).

This article is an open-access article distributed under the terms and conditions of the Creative Commons Attribution license (http://creativecommons.org/licenses/by/3.0/). 